\title{
Monitoring of glucose metabolism in patients receiving enteral nutrition
}

\section{ABSTRACT}

Hyperglycemia is frequently occurring in critically ill patients and the incidence is particularly high in patients receiving nutrition support. One of the forms of such nutrition is enteral nutrition, which is used particularly often. There are patients with type 1 diabetes, type 2 diabetes and other forms of diabetes as well as patients who have not previously been diagnosed with diabetes in this group of patients. The basis of pharmacotherapy in this case is an insulin therapy. The principles of such a therapy in patients with previously diagnosed diabetes are regulated by PTD guidelines. According to literature data, hyperglycemic patients with no previously diagnosed diabetes require special attention. The pathomechanism of these disorders is very complex and these patients require special care in determining the insulin therapy program. So far, there are no unambiguous guidelines in this area. (Clin Diabetol 2018; 7, 5: 230-233)

Key words: enteral nutrition, hyperglycemia, diabetes, non-diabetic hyperglycemia, glycemic control, insulin therapy

\section{Introduction}

Nutrition is an important component of treatment. In patients who are in a severe condition, oral nutrition is usually impossible. An option that should be preferred in hospitalized patients who can not benefit from oral nutrition is enteral nutrition (EN, enteral nutrition).

Address for correspondence: prof. Ewa Otto-Buczkowska

ul. Jasnogórska 16/21, 44-100 Gliwice

e-mail: em.buczkowski@pro.onet.pl

Clinical Diabetology 2018, 7, 5, 230-233

DOI: $10.5603 /$ DK.2018.0023

Received: 05.06.2018

Accepted: 25.09 .2018
Enteral nutrition is indicated in the prevention or treatment of malnutrition when oral food intake is impossible or insufficient. The necessary condition for its use is a properly functioning gastrointestinal tract. The indications and the way of carrying out such nutrition have been discussed in the literature [1, 2].

A special group requiring the determination of artificial nutrition are patients with cancer [3, 4]. In oncological patients, the basic energy demand is often increased. Increasing the amount of food taken by the patient, reduces the loss of body weight and tissues and improves the functional parameters of the body $[5,6]$. In this group of patients, the need to implement nutritional therapy is associated not only with surgical procedures, but also with the use of chemoradiotherapy [7].

Advances in expanding therapeutic options mean that even if cancer can not be cured, in many cases it can be transformed into chronic disease. In such cases, there is a need to protect the patients against malnutrition. In this way, enteral nutrition is often used, and in special cases of parenteral nutrition (TPN, total parenteral nutrition). A comprehensive discussion of this issue has been presented by an international group of specialists [8].

\section{Mechanisms of glucose homeostasis in patients receiving enteral nutrition}

A serious problem with the use of artificial nutrition is the occurrence of hyperglycaemia. This is a serious complication because it is associated with an increased risk of complications.

An extensive discussion of this issue was presented by Gosmanov and Umpierrez [9]. The authors pointed out that the pathogenesis of this phenomenon is complex. The role plays elevated blood glucose level, resulting from increased hepatic glucose production and reduced peripheral tissue utilization during stress, increased levels of stress hormones and cytokines as 
well as insulin resistance associated with the regulation of intracellular signaling by the insulin receptor. Not without significance for the occurrence of hyperglycaemia in patients receiving enteral nutrition is continuous intestinal exposure to the secretion and action of incretin hormones or reduced expression of glucose transporters in the intestines [10].

Many authors emphasize the importance of differentiation between stress-induced hyperglycemia (SH), newly diagnosed hyperglycaemia (NDK) and hyperglycaemia in people with established diabetes (DM) [11].

Interesting research on this issue was presented by Valizadeh Hasanloei et al. [12]. These authors found that hyperglycaemia associated with stress or trauma in patients without previously diagnosed diabetes is particularly risky. In patients hospitalized in the intensive care unit receiving enteral nutrition, the incidence of hyperglycaemia in those without previously diagnosed diabetes was $14.5 \%$.

\section{Alleviation of disorders}

Hyperglycemia may be the result of the disease itself, the treatment used, it is also a frequent side effect of artificial nutrition.

At the outset, it is necessary to determine the type of glycemic disorder and determine whether the patient has diabetes or have previously had diabetes. Therapy depends on whether they are patients with type 1 diabetes, type 2 diabetes or other types of diabetes, or whether they are patients without previously diagnosed diabetes.

The glucose level $>140 \mathrm{mg} / \mathrm{dL}(7.8 \mathrm{mmol} / \mathrm{L})$ is usually considered as the hyperglycemia in hospitalized patients. Insulin treatment is usually implemented at a glucose level of $\geq 180 \mathrm{mg} / \mathrm{dL}(10.0 \mathrm{mmol} / \mathrm{L})$. After the start of insulin therapy, glycemic maintenance within the range of $140-180 \mathrm{mg} / \mathrm{dl}(7.8-10.0 \mathrm{mmol} / \mathrm{l})$ is recommended [13]. The lower limit is assumed to be $70 \mathrm{mg} / \mathrm{dL}$ ( $3.9 \mathrm{mmol} / \mathrm{L})$. Such values are also accepted for artificially fed patients [14].

Procedures for the treatment of patients with previously diagnosed autoimmune diabetes mellitus (type 1 diabetes, type LADA diabetes), in which the basis of treatment is intensive insulin therapy, are strictly defined [15-17]. In these patients, continuous subcutaneous insulin infusion (CSII) with continuous monitoring of glucose (CGM) is most commonly used. This allows for good glycemic control and reducing the risk of hypoglycaemia $[18,19]$. Insulin analogues are usually used in these patients.

In patients with type 2 diabetes who have not previously received insulin, insulin therapy usually starts with a low dose of basal insulin with the possible addi- tion of fast-acting insulin. For enteral nutrition, 1 unit of fast-acting insulin per 10-15 $\mathrm{g}$ of carbohydrates is usually administered subcutaneously before each meal $[20,21]$.

A comprehensive discussion of this issue based on literature was presented by Corsino et al. [22]. In most patients, these authors recommend as the starting dose of insulin 0.3 to $0.5 \mathrm{U} / \mathrm{kg} \mathrm{m}$.c./day. The treatment of choice in these conditions is insulin therapy. It is recommended to maintain the blood glucose values in the range of $100-180 \mathrm{mg} / \mathrm{dl}(5.6-10.0 \mathrm{mmol} / \mathrm{l})$.

The subject of discussion is the treatment of patients with type 2 diabetes and patients with hyperglycaemia without previously diagnosed diabetes. According to current recommendations, these patients should be treated with insulin therapy [15]. This applies to patients with type 2 diabetes treated with oral hypoglycaemic agents. This also applies to patients without previously diagnosed diabetes who have experienced glucose homeostasis disorders as a result of septic stress or trauma [23].

\section{Insulin therapy during enteral nutrition}

Extensive discussion of the issue of glycemic control in demanding patients of nutrition on the basis of a literature review recently presented by Vennard et al. [24]. The authors state that the best glycemic control is ensured by continuous infusion of insulin, however administering insulin subcutaneously to patients fed enterally or parenterally is a safe and effective way of treating hyperglycaemia. However, there are no definitive findings regarding insulin therapy in such patients. The authors believe that further randomized studies are needed to determine the optimal therapy for hyperglycaemia in patients requiring enteral or parenteral nutrition.

McCulloch et al. based on a review of the literature, found that in patients fed parenterally, the dose necessary for metabolic insulin balancing varies within very wide limits [25]. Recently, the American authors presented the analysis of glycemic control in enteric fed patients [26]. Fatati et al. presented results in the group of patients with type 2 diabetes mellitus and without previously diagnosed diabetes, in which the use of insulin therapy during enteral or parenteral feeding was found [27]. The Spanish authors have made recommendations on insulin dosing when switching from intravenous (IV) insulin to subcutaneous (S.C) insulin delivery [28]. The authors pointed out that at the transition from IV to S.C. the initial dose of insulin at $50 \%$ of the previous dose is suitable for enterally fed (EN) patients, but not adequate for patients remaining on parenteral nutrition (TPN). 
Difficulties in metabolic glycemic control in patients with previously diagnosed diabetes requiring continuous enteral nutrition therapy (CENT) were noted by Hijaze and Szalat [29]. Verçosa Viana et al. [30] also analyzed the literature regarding insulin therapy in patients with nutritional support (NS) [30]. Attempts are made to determine the composition of the food used in nutrition support in oncological patients [31]. Even though, there are no established guidelines, one can use the guidelines developed for patients in critical conditions [32-34].

\section{Summary}

The use of artificial nutrition in seriously ill patients is an important therapeutic challenge. These patients usually due to the underlying disease have various metabolic disorders, including glucose metabolism disorders. One of the most physiological forms of nutrition support is enteral nutrition. To maintain glycemic control, pharmacotherapy is required in these patients. At present, insulin therapy is the treatment of choice regardless of the underlying disorders. Rules for its use in patients with insulin-dependent diabetes are clarified. More discussion raises such a therapy in patients without previously diagnosed diabetes. According to the literature, these patients are particularly vulnerable to the adverse course of such disorders and require very careful metabolic control and individually selected therapy. At the moment, there are no explicit recommendations regarding the nutritional treatment of oncological patients and, according to many authors, this issue requires urgent elaboration.

\section{REFERENCES}

1. Hudson L, Chittams J, Griffith C, et al. Malnutrition Identified by Academy of Nutrition and Dietetics/American Society for Parenteral and Enteral Nutrition Is Associated With More 30-Day Readmissions, Greater Hospital Mortality, and Longer Hospital Stays: A Retrospective Analysis of Nutrition Assessment Data in a Major Medical Center. JPEN J Parenter Enteral Nutr. 2018; 42(5): 892-897, doi: 10.1002/jpen.1021, indexed in Pubmed: 29385244

2. McClave SA, Taylor BE, Martindale RG, et al. Society of Critical Care Medicine, American Society for Parenteral and Enteral Nutrition, Society of Critical Care Medicine, American Society of Parenteral and Enteral Nutrition. Guidelines for the Provision and Assessment of Nutrition Support Therapy in the Adult Critically III Patient: Society of Critical Care Medicine (SCCM) and American Society for Parenteral and Enteral Nutrition (A.S.P.E.N.). JPEN J Parenter Enteral Nutr. 2016; 40(2): 159-211, doi: 10.1177/0148607115621863.

3. Goéré D, Cunha ASa. Parenteral and enteral nutritional support (excluding immunonutrition). J Visc Surg. 2015; 152(Suppl 1): S8-SS13, doi: 10.1016/S1878-7886(15)30004-7, indexed in Pubmed: 26315578.

4. Klek S, Szybinski P, Szczepanek K. Perioperative immunonutrition in surgical cancer patients: a summary of a decade of research. World J Surg. 2014; 38(4): 803-812, doi: 10.1007/s00268-0132323-z, indexed in Pubmed: 24178185.
5. Garth AK, Newsome CM, Simmance N, et al. Nutritional status, nutrition practices and post-operative complications in patients with gastrointestinal cancer. J Hum Nutr Diet. 2010; 23(4): 393-401, doi: 10.1111/j.1365-277X.2010.01058.x, indexed in Pubmed: 20337847.

6. Gómez Sánchez MaB, García Talavera Espín NV, Monedero Saiz T, et al. Evaluation of perioperative nutritional therapy in patients with gastrointestinal tract neoplasms. Nutr Hosp. 2011; 26(5): 1073-1080, doi: 10.1590/S021216112011000500023, indexed in Pubmed: 22072355.

7. Mulasi U, Vock DM, Kuchnia AJ, et al. Malnutrition Identified by the Academy of Nutrition and Dietetics and American Society for Parenteral and Enteral Nutrition Consensus Criteria and Other Bedside Tools Is Highly Prevalent in a Sample of Individuals Undergoing Treatment for Head and Neck Cancer. JPEN J Parenter Enteral Nutr. 2016 [Epub ahead of print]; 42(1): 139-147, doi: 10.1177/0148607116672264, indexed in Pubmed: 27875280.

8. Arends J, Bachmann P, Baracos V, et al. ESPEN guidelines on nutrition in cancer patients. Clin Nutr. 2017; 36(1): 11-48, doi: 10.1016/j.clnu.2016.07.015, indexed in Pubmed: 27637832.

9. Gosmanov A, Umpierrez G. Management of Hyperglycemia During Enteral and Parenteral Nutrition Therapy. Current Diabetes Reports. 2012; 13(1): 155-162, doi: 10.1007/s11892-012-0335-y, indexed in Pubmed: 21997598.

10. Deane AM, Rayner CK, Keeshan A, et al. The effects of critical illness on intestinal glucose sensing, transporters, and absorption. Crit Care Med. 2014; 42(1): 57-65, doi: 10.1097/ /CCM.0b013e318298a8af, indexed in Pubmed: 23963126.

11. Davidson P, Kwiatkowski CA, Wien M. Management of Hyperglycemia and Enteral Nutrition in the Hospitalized Patient. Nutr Clin Pract. 2015; 30(5): 652-659, doi: 10.1177/0884533615591057, indexed in Pubmed: 26084507.

12. Valizadeh Hasanloei MA, Shariatpanahi ZV, Vahabzadeh D, et al. Non-diabetic Hyperglycemia and Some of Its Correlates in ICU Hospitalized Patients Receiving Enteral Nutrition. Maedica (Buchar). 2017; 12(3): 174-179, indexed in Pubmed: 29218064.

13. American Diabetes Association. Diabetes care in the hospital. Sec. 14. In Standards of Medical Care in Diabetes - 2017. Diabetes Care. 2017; 40(Suppl. 1): S120-S112.

14. McMahon MM, Nystrom E, Braunschweig C, et al. American Society for Parenteral and Enteral Nutrition. A.S.P.E.N. clinical guidelines: nutrition support of adult patients with hyperglycemia. JPEN J Parenter Enteral Nutr. 2013; 37(1): 23-36, doi: 10.1177/0148607112452001, indexed in Pubmed: 22753619.

15. Diabetology C. 2018 Guidelines on the management of diabetic patients. A position of Diabetes Poland. Clinical Diabetology. 2018; 7(1): 1-90, doi: 10.5603/dk.2018.0001.

16. Acerini $C$, Craig ME, de Beaufort $C$, et al. Introduction to ISPAD Clinical Practice Consensus Guidelines 2014 Compendium. Pediatr Diabetes. 2014; 15(5, Suppl 20): 1-3, doi: 10.1111/pedi.12182, indexed in Pubmed: 25182304.

17. American Diabetes Association. Introduction: Standards of Medical Care in Diabetes - 2018. Diabetes Care. 2017; 41(Suppl 1): S1-S2, doi: 10.2337/dc18-sint01.

18. Aloi J, Bode BW, Ullal J, et al. Comparison of an Electronic Glycemic Management System Versus Provider-Managed Subcutaneous Basal Bolus Insulin Therapy in the Hospital Setting. J Diabetes Sci Technol. 2017; 11(1): 12-16, doi: 10.1177/1932296816664746, indexed in Pubmed: 27555601.

19. Leelarathna L, English SW, Thabit H, et al. Feasibility of fully automated closed-loop glucose control using continuous subcutaneous glucose measurements in critical illness: a randomized controlled trial. Crit Care. 2013; 17(4): R159, doi: 10.1186/ /cc12838, indexed in Pubmed: 23883613.

20. Korytkowski MT, Salata RJ, Koerbel GL, et al. Insulin therapy and glycemic control in hospitalized patients with diabetes during enteral nutrition therapy: a randomized controlled clinical trial. Diabetes Care. 2009; 32(4): 594-596, doi: 10.2337/dc08-1436, indexed in Pubmed: 19336639. 
21. Moghissi ES, Korytkowski MT, DiNardo M, et al. American Association of Clinical Endocrinologists, American Diabetes Association. American Association of Clinical Endocrinologists and American Diabetes Association consensus statement on inpatient glycemic control. Diabetes Care. 2009; 32(6): 1119-1131, doi: 10.2337/ /dc09-9029, indexed in Pubmed: 19429873.

22. Corsino L, Dhatariya K, Umpierrez G. Management of Diabetes and Hyperglycemia in Hospitalized Patients. In: De Groot $\mathrm{U}$, Chrousos G, Dungan K. ed. Endotext [Internet]. com, Inc, South Dartmouth (MA) 2017.

23. Otto-Buczkowska E, Dworzecki T, Mazur-Dworzecka U, et al. Alterations in blood glucose homeostasis during septic or injury stress - hyperglycemia. Fam Med Primary Care Rev. 2008; 10(2): 197-205.

24. Vennard KC, Selen DJ, Gilbert MP. The management of hyperglycemia in noncritically-ill hospitalized patients treated with continuous enteral or parenteral nutrition. Endocr Pract. 2018 [Epub ahead of print], doi: 10.4158/EP-2018-0150, indexed in Pubmed: 30035626.

25. McCulloch A, Bansiya V, Woodward JM. Addition of Insulin to Parenteral Nutrition for Control of Hyperglycemia. JPEN J Parenter Enteral Nutr. 2018; 42(5): 846-854, doi: 10.1177/0148607117722750, indexed in Pubmed: 28792863.

26. Vallumsetla N, Epp L, Hurt RT, et al. Effect of Home Enteral Nutrition on Diabetes and Its Management. Nutr Clin Pract. 2018 [Epub ahead of print], doi: 10.1002/ncp.10104, indexed in Pubmed: 30004594.

27. Fatati G, Di Donato A, Grandone I, et al. Impact of Insulin Degludec in Hospitalized Patients With and Without Type 2 Diabetes Requiring Parenteral/Enteral Nutrition: An Observational Study.
Adv Ther. 2018; 35(6): 809-816, doi: 10.1007/s12325-0180709-x, indexed in Pubmed: 29777522.

28. Ramos A, Zapata L, Vera P, et al. Transition from intravenous insulin to subcutaneous long-acting insulin in critical care patients on enteral or parenteral nutrition. Endocrinol Diabetes Nutr. 2017; 64(10): 552-556, doi: 10.1016/j.endinu.2017.08.005, indexed in Pubmed: 29179857.

29. Hijaze D, Szalat A. Retrospective Evaluation of Glycemic Control With Basal-Bolus or Neutral Protamine Hagedorn Insulin Regimens in Patients Receiving Continuous Enteral Nutrition Therapy in Medicine Wards. Nutr Clin Pract. 2017; 32(4): 557-562, doi: 10.1177/0884533617692765, indexed in Pubmed: 28760108.

30. Verçoza Viana M, Verçoza Viana L, Tavares AL, et al. Insulin Regimens to Treat Hyperglycemia in Hospitalized Patients on Nutritional Support: Systematic Review and Meta-Analyses. Ann Nutr Metab. 2017; 71(3-4): 183-194, doi: 10.1159/000481355, indexed in Pubmed: 29017173.

31. Kapała A. Dieta w chorobie nowotworowej. Buchmann, Warszawa 2018.

32. Kumpf VJ, de Aguilar-Nascimento JE, Diaz-Pizarro Graf Jl, et al. FELANPE, American Society for Parenteral and Enteral Nutrition. ASPEN-FELANPE Clinical Guidelines. JPEN J Parenter Enteral Nutr. 2017; 41(1): 104-112, doi: 10.1177/0148607116680792, indexed in Pubmed: 27913762

33. Patkova A, Joskova V, Havel E, et al. Energy, Protein, Carbohydrate, and Lipid Intakes and Their Effects on Morbidity and Mortality in Critically III Adult Patients: A Systematic Review. Adv Nutr. 2017; 8(4): 624-634, doi: 10.3945/an.117.015172, indexed in Pubmed: 28710148.

34. Schetz M, Casaer MP, Van den Berghe G. Does artificial nutrition improve outcome of critical illness? Crit Care. 2013; 17(1): 302, doi: 10.1186/cc11828, indexed in Pubmed: 23375069. 